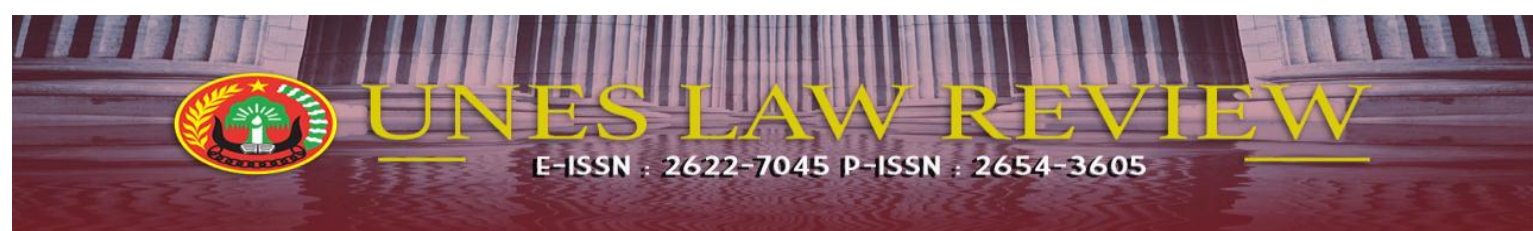

Email : uneslawreview@gmail.com Online : http://review-unes.com/index.php/law/index

Volume 1, Issue 3, Maret, 2019

E-ISSN : 2622-7045

P-ISSN : 2654-3605

\title{
EFEKTIVITAS PENGGUNAAN KEKUATAN OLEH KEPOLISIAN DALAM MENANGANI AKSI UNJUK RASA ANARKIS DI KOTA PADANG (STUDI PADA SATSABHARA POLRESTA PADANG)
}

\author{
${ }^{1}$ Sigit Saputra, ${ }^{2}$ Otong Rosadi \\ ${ }^{1}$ Program Magister Ilmu Hukum, Universitas Ekasakti \\ Email: wab30_sigit@yahoo.com \\ ${ }^{2}$ Program Magister Ilmu Hukum, Universitas Ekasakti \\ Email: otongrosadi@ review-unes.com
}

\begin{abstract}
Broadly speaking, gather and issue opinions as stipulated in Article 28 (e) Paragraph (3) of the 1945 Constitution, independence expresses opinion as stipulated in Law No. 9 of 1998, then everyone has the right to freedom of association. The practice is in the field, many demonstrations taste or demonstration that ended in riots that led to anarchists. In carrying out the task of handling mass riots during the Police demonstration using 1) Perkap No. 16 of 2006 concerning Mass Control Guidelines, 2) Protap/1/X/2010 concerning Countermeasures for Anarchy, 3) Perkap No. 1 of 2012 concerning Mass Unraveling Platoon, 4 ) Perkap No. 7 of 2012 concerning Procedures for Organizing Services, Safeguards and Handling of Cases of Public Opinion. The problems in this thesis are: First, how is the use of force by the Padang Police Satsabhara in dealing with anarchist demonstrations in Padang City? Second, the obstacles encountered by Padang Satsabhara in handling anarchist demonstrations in Padang City and how to overcome these obstacles? Third, how effective is the use of force by the Padang Police Satsabhara in handling anarchist demonstrations in Padang City? The specification of this research is a descriptive analytical study. The approach used is normative juridical as the main approach and supported by an empirical juridical approach. The data used is secondary data and primary data. The data obtained were analyzed qualitatively and presented descriptively analytically. Based on the research and discussion, it can be seen that: First, the use of force by Satsabhara Polresta Padang in handling anarchist demonstrations in Padang City includes organizing services, organizing security and handling cases, carried out by using force, such as in the preparation stage before the demonstration, in the event of anarchist demonstrations and at the time of anarchist demonstration activities are over. Second, the obstacles encountered by Padang Satsabhara Polresta in handling anarchist demonstrations in Padang City are human rights problems, provocation from certain parties, legal unconsciousness of the community and lack of coordination with the Police and related agencies. Whereas the efforts made in handling the demonstration are; $a$ ). pre-emptive effort, $b$ ). preventive efforts, $c$ ). repressive efforts. Then the Police also made several efforts, namely by increasing the professionalism of members of the Police, coordinating with relevant agencies and conducting legal counseling to the community. Third, the effectiveness of the use of force by the Padang Police Satsabhara in handling anarchist demonstrations in Padang City based on its duties and authorities has shown performance in police actions to deal with anarchic demonstrations in Padang City that are optimal with the number of anarchist rallies in Padang City that have been handled.
\end{abstract}

Keywords: Efektivitas, Aksi Unjuk Rasa Anarkis 


\section{PENDAHULUAN}

Undang-undang

memberikan

perlindungan kepada setiap setiap orang

berhak atas kebebasan berserikat, berkumpul dan mengeluarkan pendapat sebagaimana dirumuskan dalam Pasal 28 (e) Ayat (3) Undang-Undang Dasar Negara Republik Indonesia Tahun 1945 bahwa kemerdekaan berserikat dan berkumpul mengeluarkan pikiran dengan lisan, tulisan dan sebagainya ditetapkan dengan Undang-undang. Namun dengan adanya ketentuan tersebut menimbulkan asumsi atau persepsi masyarakat yang lebih luas, bahkan dalam melakukan aksinya pun tanpa mengontrol diri, yang akhirnya menuju pada anarki yakni penjarahan, pembakaran, pembunuhan dan pemerkosaan yang akibatnya dirasakan oleh masyarakat itu sendiri. ${ }^{1}$

Dalam praktiknya dilapangan, banyak aksi unjuk rasa ataupun demonstrasi yang berakhir dengan kerusuhan yang mengarah pada anarki. Hal tersebut disebabkan oleh faktor-faktor dari dalam dan luar demonstran itu sendiri. Unjuk rasa yang apabila tidak tertangani dengan baik maka akan menjadi kekacauan yang mengakibatkan kerugian yang tidak sedikit yaitu korban jiwa dan korban harta benda bahkan aktivitas transportasi dan ekonomi menjadi terhambat dikarenakan kerusuhan massa yang bersifat

\footnotetext{
${ }^{1}$ Kunarto, Merenungi Kiprah Polri Menghadapi Gelora Anakhi, Cipta Manunggal, Jakarta, 1999, hlm.113.
}

anarki tersebut. Namun tentunya pihak Kepolisian tidak tinggal diam dalam mengantisipasi keadaan tersebut. Hal ini dibuktikan bahwa Polri telah mengeluarkan peraturan tentang pengendalian unjuk rasa yaitu Peraturan Kapolri Nomor 16 Tahun 2006 tentang Pedoman Pengendalian Massa, Prosedur Tetap Nomor: Protap/1/X/2010 tentang Penanggulangan Anarki, Peraturan Nomor 1 Tahun 2012 tentang Peleton Pengurai Massa, Peraturan Kapolri Nomor 7 Tahun 2012 tentang Tata Cara Penyelenggaraan Pelayanan, Pengamanan dan Penanganan Perkara Penyampaian Pendapat di Muka Umum. Peraturan tersebut dikeluarkan dengan tujuan untuk memberikan pedoman kepada personil Polri dalam melaksanakan tugas penanganan kerusuhan massa pada saat terjadi demonstrasi.

Permasalahan yang dihadapi Polri dalam tugas saat ini bagaimana menciptakan rasa aman masyarakat menghadapi perkembangan demokrasi dengan bermunculan aksi aksi massa seperti demonstrasi yang sewaktu-waktu dapat menyulut terjadinya kerusuhan massal. Profesionalisme Polri dituntut untuk mewujudkan kepastian hukum baik kepastian dalam hukum maupun kepastian karena hukum, melalui pemupukan pengendalian massa secara tegas, berdasarkan hukum dan manusiawi, dengan membekali para anggota 
Poliri dan keterampilan menggunakan peralatan pengendalian massa. ${ }^{2}$

Fokus penelitian ini ditujukan pada hal-hal yang berkaitan dengan permasalahan yang dihadapi Polri dalam tugas saat ini adalah bagaimana menciptakan rasa aman masyarakat menghadapi perkembangan demokrasi dengan bermunculan aksi-aksi massa seperti demonstrasi yang sewaktuwaktu dapat menyulut terjadinya kerusuhan massa. Untuk itu diperlukan kesiapan dari aparat Kepolisian untuk dapat mencegah dan menanggulangi jika terjadinya kerusuhan massa pada saat unjuk rasa, supaya terjaga keamanan dan ketertiban masyarakat.

\section{METODE PENELITIAN}

Untuk menjawab permasalahan dalam tesis ini dilakukan pendekatan yuridis normatif yang didukung oleh pendekatan yuridis empiris dengan menggunakan data sekunder dan data primer yang diperoleh melalui studi kepustakaan dan hasil penelitian.

Spesifikasi penelitian ini adalah deskriptif analitis yaitu untuk menggambarkan sekaligus menganalisis peraturan perundang-undangan dan teori-teori hukum yang berkaitan dengan permasalahan yang dibahas.

${ }^{2}$ Bibit Samad Rianto, Pemikiran Menuju Polri Yang Proesional, Mandiri, Berwibawa Dan Dicintai Rakyat, Ratu Agung, Jakarta, 2006, hlm.36.
HASIL DAN PEMBAHASAN

Penggunaan Kekuatan oleh Satsabhara Polresta Padang Dalam Menangani Aksi Unjuk Rasa Anarkis di Kota Padang

Unjuk rasa merupakan kegiatan yang dilakukan oleh seorang atau lebih untuk mengeluarkan pikiran dengan lisan, tulisan, dan sebagainya secara demonstratif di muka umum. Selama pelaksanaan unjuk rasa, dimana diawali dengan suasana damai dapat berubah drastis menjadi anarkis sehingga mengganggu keamanan dan ketertiban masyarakat. Keadaan perubahan secara drastis menjadi kondisi yang mencekam di sebut kontinjensi.

Pada setiap pelaksanaan pengendalian massa unjuk rasa, maka setiap anggota kepolisian memiliki kewajiban dan laranganlarangan. Adapun larangan tersebut yakni: a) bersikap arogan dan terpancing oleh perilaku massa; b) melakukan tindakan kekerasan yang tidak sesuai dengan prosedur; c) membawa peralatan di luar peralatan Dalmas; d) membawa senjata tajam dan peluru tajam; e) keluar dari Ikatan Satuan/Formasi dan melakukan pengejaran massa secara perorangan; f) mundur membelakangi massa pengunjuk rasa; g) mengucapkan kata-kata kotor, pelecehan seksual/perbuatan asusila, memaki-maki pengunjuk rasa; dan h) melakukan perbuatan lainnya yang melanggar peraturan perundang-undangan.

Berdasarkan ketentuan Pasal 18 Ayat (1) Undang-undang Nomor 2 Tahun 2002 
tentang Kepolisian Negara Republik Indonesia, maka untuk kepentingan umum, pejabat Kepolisian Negara Republik Indonesia dalam melaksanakan tugas dan wewenangnya dapat bertindak menurut penilaiannya sendiri. Ayat (2) mengatur bahwa pelaksanaan ketentuan sebagaimana dimaksud dalam Ayat (1) hanya dapat dilakukan dalam keadaan yang sangat perlu dengan memperhatikan peraturan perundang-undangan, serta Kode Etik Profesi Kepolisian Negara Republik Indonesia.

Dalam perkembangan yang lebih luas, berbagai aksi unjuk rasa dan atau demonstrasi yang awalnya berjalan kondusif, namun karena adanya faktor-faktor yang mempengaruhi terjadinya aksi anarkis atau tidak tertangani dengan baik, dalam perkembangannya terjadi bentrokan dengan aparat keamanan dan cenderung bertindak anarkis, seperti terjadinya kerusuhan yang berdampak pada pembakaran, penyanderaan dan perusakan fasilitas umum lainnya, sehingga situasi keamanan dan ketertiban masyarakat menjadi tidak menentu. Dalam mengantisipasi kondisi demikian, tentunya penggunaan kekuatan oleh Satsabhara Polresta Padang dalam menangani aksi unjuk rasa anarkis di Kota Padang, sebagai aparat yang memiliki tugas pokok dalam memelihara keamanan dan ketertiban, menegakkan hukum, serta memberikan perlindungan, kepada masyarakat dituntut agar mengantisipasi keadaan tersebut dengan baik, dengan melakukan pola pelayanan, dengan mengutamakan strategi pencegahan (pre-emtif) dan pengamanan (preventif), dalam mengantisipasi aksi unjuk rasa yang bersifat anarkis, sehingga dapat dieleminir dan tidak meluas.

Upaya yang dilakukan Satsabhara Polresta Padang dalam menangani aksi unjuk rasa anarkis di Kota Padang yaitu dengan mengacu pada Standar Oprasional Prosedur dan Prosedur Tetap Kepolisian Negara Republik Indonesia Nomor 1 Tahun 2010 tentang Penanggulangan Anarki, yaitu:

1. Upaya pre-emtif adalah tindakan awal yang dilakukan pihak Kepolisian dalam memberikan himbauan dan mendekati kelompok unjuk rasa agar berunjuk rasa dengan tertib. Hal ini ditujukan agar jalannya unjuk rasa dapat berjalan dengan tertib dan tidak terjadi hal-hal yang merugikan masyarakat lalu memberitahukan lebih awal kepada instansi terkait yang akan dijadikan sasaran aksi unjuk rasa dan atau demonstrasi;

2. Upaya preventif merupakan upaya yang dilakukan pihak Kepolisian dalam melakukan tugas sesuai dengan Prosedur tetap (Protap). Hal ini dimaksudkan agar pihak Kepolisian baik perorangan dan unit satuan dalam mengambil tindakan tidak di pandang berlebihan oleh masyarakat. Pihak Satsabhara Polresta Padang dalam mengambil tindakan harus jeli dalam 
melihat kemungkinan-kemungkinan yang dapat terjadi dalam unjuk rasa agar dapat meminimalisir bahaya atau ancaman dari dampak unjuk rasa dan atau demonstrasi tersebut, sehingga tidak terjadi kerusuhan massa dengan salah satu cara yaitu mengosongkan jalan;

3. Upaya Represif merupakan tidakan terakhir pihak Satsabhara Polresta Padang ketika aksi unjuk rasa dan atau demonstrasi sudah tidak terkendali lagi dan mengarah pada aksi kerusuhan. Dalam melakukan tindakan represif, pihak Satsabhara Polresta Padang dalam menangani aksi unjuk rasa anarkis harus melakukan sesuai dengan Protap (prosedur tetap). Tindakan ini dilakukan karena situasi yang tidak kondusif dan tidak memungkinkan lagi untuk dicegah sehingga pihak penggunaan kekuatan oleh Satsabhara Polresta Padang dalam menangani aksi unjuk rasa anarkis di Kota Padang perlu melakukan tindakan tersebut guna mengantisipasi agar dampak kerusuhan tersebut tidak meluas, sebagaimana diatur dalam Protap Kepolisian Nomor 1 Tahun 2010 Tentang Penanggulangan Anarki.

\section{Kendala-kendala Yang Ditemui Satsabhara Polresta Padang Dalam Menangani Aksi Unjuk Rasa Anarkis di Kota Padang dan Upaya Untuk Mengatasi Kendala Tersebut Polresta Padang dalam menangani aksi unjuk rasa anarkis guna melaksanakan perannya sebagai pengamanan jalannya unjuk}

rasa dan mencegah terjadinya kerusuhan memiliki beberapa kendala. Adapun kendala yang ditemui Kepolisian selaku pengendalian massa (Dalmas), yaitu:

a. Masalah Hak Azasi Manusia

$$
\text { Peran Dalmas untuk }
$$

menanggulangi demonstrasi sering upaya represif dari Kepolisian berbentur dengan Hak Asasi Manusia. Pasukan Pengendalian Massa yang melakukan pengejaran dan pemukulan kepada pengunjuk rasa yang anarkis sering dituding melakukan Pelanggaran Hak Asasi Manusia. Pelanggaran hak asasi manusia sebagaimana dimaksud pada Pasal 1 butir (6) Undang-undang Nomor 39 Tahun 1999 tentang Hak Asasi Manusia bahwa setiap perbuatan seseorang/kelompok termasuk aparat negara baik disengaja maupun tidak disengaja atau yang secara melawan hukum mengurangi, menghalangi, membatasi, atau mencabut HAM seseorang atau kelompok yang dijamin oleh Undang-undang ini, dan tidak dikhawatirkan tidak akan memperoleh penyelesaian hukum yang adil dan benar, berdasarkan mekanisme hukum yang berlaku.

Tugas represif adalah tugas penegakan hukum oleh Polri yang dalam pelaksanaannya tidak sebebas tugas preventif, tapi harus dibatasi dengan hukum dan undang-undang yang berlaku 
atau dengan kata lain harus didasarkan dengan azas legalitas. Semua itu dimaksudkan agar Polri dalam bertindak tidak melampaui batas kewenangannya atau tidak melanggar HAM pada umumnya. Dimanapun penyalahgunaan wewenang itu memang selalu saja dimungkinkan untuk terjadi. Luasnya tugas yang harus ditangani menyebabkan kontrol atas penggunaan kewenangan itu menjadi sulit, yang lalu membuka peluang luas terjadinya pelanggaran atau penyalahgunaan kewenangan.

b. Ketidaksadaran Hukum Masyarakat

Dalam melakukan unjuk rasa ada prosedur yang harus dipenuhi dan ada pula peraturan yang tidak boleh dilanggar. Namun pecahnya kerusuhan pada saat unjuk rasa sering terjadi karena masih rendahnya kesadaran hukum. Kurangnya pengetahuan masyarakat pengunjuk rasa akan peraturan yang berlaku dapat menjadi kendala dalam penangulangan kerusuhan pada saat unjuk rasa. Kualitas pendidikan yang relatif rendah berpengaruh terhadap pengendalian emosi yang gampang meledak. Kualitas emosional seperti ini akan mudah dimanfaatkan oleh orang atau kelompokkelompok tertentu untuk menciptakan kerusuhan untuk kepentingan orang atau kelompok tertentu. Kepercayaan masyarakat terhadap penegakan hukum oleh aparat pemerintah juga sudah menurun sehingga masyarakat kadang berfikir untuk main hakim sendiri.

c. Kurangnya Koordinasi dengan Instansi Terkait

Kurangnya koordinasi bukan hanya pada tahap persiapan saja atau sebelum dilakukan unjuk rasa, tetapi juga pada saat berlangsungnya unjuk rasa. Dalmas dalam hal ini bukan hanya sebagai pengaman dalam aksi demonstrasi tetapi juga sebagai perantara antara pengunjuk rasa dengan pihak atau instansi yang dituju. Koordinasi pada saat terjadinya unjuk rasa dapat berupa negosiasi yang dilakukan oleh pihak dan instansi yang dituju dengan pengunjuk rasa melalui negosiator dari kepolisian pada saat unjuk rasa. Dalam hal ini instansi atau pihak terkait haruslah aktif melakukan komunikasi dengan pihak Kepolisian supaya tidak timbul anarkis akibat ketidakpuasan massa pengunjuk rasa dengan hasil atau solusi yang didapat dari kegiatan berunjuk rasa tersebut.

Satsabhara Polresta Padang dalam menangani aksi unjuk rasa anarkis berupaya melakukan tindakan mengayomi dan melindungi Demonstran, namun kurang intensifnya negosiasi dengan Korlap dan kurang intensifnya tugas Intelegen, berakibat Demonstran mudah terprovokasi sehingga berujung pada kerusuhan. Tidak intensifnya pendekatan yang bersifat preemtif, preventif 
dan persuasif mempersulit penyelesaian konflik ketika terjadi demonstrasi.

Efektifitas Penggunaan Kekuatan oleh Satsabhara Polresta Padang Dalam Menangani Aksi Unjuk Rasa Anarkis di Kota Padang

Mekanisme penyelenggaraan unjuk rasa dilakukan dengan penyampaian secara tertulis kepada kepolisian setempat sebelum pelaksanaan kegiatan. Dalam pelaksanaannya sendiri, penyelenggara harus melakukan koordinasi dengan aparat dan lembaga terkait demi kelancaran dan pengamanan kegiatan unjuk rasa. Unjuk rasa itu sendiri tidak dapat dilakukan di tempat-tempat tertentu yang dilarang, yakni: (a) tempat ibadah, rumah sakit, pelabuhan udara atau laut, stasiun kereta api, terminal angkutan darat;

objek-objek vital nasional dalam radius kurang dari 500 meter dari pagar luar; (c) instalasi militer dalam radius kurang dari 150 meter dari pagar luar; (d) di lingkungan istana kepresidenan (Presiden dan Wakil Presiden) dalam radius kurang dari 100 meter dari pagar luar; dan (e) tempat yang rutenya melalui atau melintasi wilayah Istana Kepresidenan dan tempat-tempat ibadah pada saat ibadah sedang berlangsung.

Efektifitas penggunaan kekuatan oleh Satsabhara Polresta Padang dalam menangani aksi unjuk rasa anarkis di Kota Padang telah menempatkan antara hak dan kewajiban pada setiap warganegara dilakukan secara seimbang. Satsabhara Polresta Padang dalam menangani aksi unjuk rasa anarkis dengan tindakan yang humanis (berperikemanusiaan) dengan menghormati HAM (Hak Asasi Manusia), mengedepankan musyawarah mufakat, dilakukan dengan tindakan preemtif, persuasif dan preventif. Jika kondisi membahayakan kepentingan bersama maka tindakan represif perlu dilakukan sebagai supremasi hukum dengan berdasarkan asas legalitas, nesesitas, proporsionalitas, dan akuntabilitas.

Penanganan demonstrasi dari paradigma berorientasi menggunakan metode Crowd Control (mengendalikan massa dengan persiapan persenjataan menghadang Demonstran) kearah memfasilitasi kebutuhan massa demonstrasi, dengan tindakan yang humanis, dengan mengutamakan pendekatan negosiasi dan mendorong proses mediasi. Satsabhara Polresta Padang sebagai pelindung memberikan fasilitas berupa jaminan keamanan kepada Demonstran untuk menghindari tindakan yang otoriter dari pihak-pihak terkait.

\section{PENUTUP}

Penggunaan kekuatan oleh Satsabhara Polresta Padang dalam menangani aksi unjuk rasa anarkis di Kota Padang meliputi penyelenggaraan pelayanan, penyelenggaraan pengamanan dan penanganan perkara, dilakukan dengan cara menggunaan kekuatan, seperti dilakukan pada tahap persiapan sebelum kegiatan unjukrasa. Pada tahap ini Kepolisian, khususnya pihak Satsabhara 
Polresta Padang melakukan rapat koordinasi, kesiapan pasukan Dalmas, melakukan pengecekan peralatan Dalmas, mempelajari karakteristik pengunjuk, mempelajari isu yang dibawakan, mempelajari objek unjuk rasa, menyiapkan rute pasukan Dalmas menuju objek dan rute penyelamatan (escape) bagi pejabat VVIP/VIP dan pejabat penting lainnya serta Rencana urutan dan langkah dan tindakan yang akan dilakukan oleh satuan Dalmas. Pada saat terjadi unjuk rasa ada tahapan yang dilakukan tergantung pada perkembangan situasi dilapangan, yaitu: 1) tahap Situasi Tertib (hijau). Pada tahap Ini diturunkan pasukan Dalmas awal, 2) t ahap situasi tidak tertib (kuning).Pada tahap ini diturunkan pasukan Dalmas lanjutan, 3) tahap melanggar h u k u m (merah). Pada tahap ini diturunkan Detasemen atau Kompi (PHH). Selanjutnya setelah kegiatan unjuk rasa selesai. Setelah unjuk rasa selesai maka dilakukan konsolidasi pasukan Dalmas, pengecekan pasukan serta pasukan Dalmas. Kendala-kendala yang ditemui Satsabhara Polresta Padang dalam menangani aksi unjuk rasa anarkis di Kota Padang adalah permasalahan HAM, adanya provokasi dari pihak tertentu, ketidaksadaran hukum masyarakat dan kurang koordinasi dengan pihak Kepolisian dan instansi yang terkait. Sedangkan upaya-upaya yang dilakukan dalam penanganan demonstrasi di wilayah hukum Polresta Padang yaitu; a). upaya preemtif memberikan himbauan kepada pengunjuk rasa tentang tata cara demonstrasi yang baik serta memberitahukan kepada instansi terkait yang menjadi titik sasaran unjuk rasa dan atau demonstrasi, b). upaya preventif dilakukan oleh pihak Kepolisian dalam melakukan tugas sesuai dengan Prosedur tetap (Protap). Hal ini dimaksudkan agar pihak Kepolisian baik perorarangan dan unit satuan dalam mengambil tindakan tidak dipandang berlebihan oleh masyarakat, c). upaya represif merupakan tidakan terakhir pihak Kepolisian ketika aksi unjuk rasa sudah tidak terkendali lagi dan telah mengarah pada aksi kerusuhan. Kemudian pihak Kepolisian juga melakukan beberapa upaya, yaitu dengan meningkatkan profesionalisme anggota Kepolisian, mengadakan koordinasi dengan instansi terkait serta mengadakan penyuluhan hukum kepada masyarakat. Efektifitas penggunaan kekuatan oleh Satsabhara Polresta Padang dalam menangani aksi unjuk rasa anarkis di Kota Padang berdasarkan tugas dan wewenangnya telah menunjukkan kinerja dalam tindakan Kepolisian guna menangani aksi unjuk rasa anarkis di Kota Padang yang optimal dengan jumlah aksi unjuk rasa anarkis di Kota Padang yang sudah ditangani. Pengamanan unjuk rasa merupakan bagian dari peran dari fungsi kepolisian. Unjuk rasa merupakan salah satu bentuk dalam rangka penyampaian pendapat di muka umum dimana menyampaikan pendapat di muka umum tersebut merupakan hak setiap warga negara yang diatur dalam Pasal 28 E 
Undang-Undang Dasar Negara Republik

Indonesia Tahun 1945.

\section{DAFTAR PUSTAKA}

Buku

Anton Tabah, Membangun Polri yang Kuat (Belajar dari Macan-macan Asia), Mitra Hardhasuma, Jakarta, 2003.

Bibit Samad Rianto, Pemikiran Menuju Polri Yang Proesional, Mandiri, Berwibawa Dan Dicintai Rakyat, Ratu Agung, Jakarta, 2006.

Kunarto, Merenungi Kiprah Polri Menghadapi Gelora Anakhi, Cipta Manunggal, Jakarta, 1999.

Suparlan, Hukum Kepolisian, Cipta Manunggal, Jakarta, 2001.

\section{Undang-undang}

Undang-Undang Dasar Negara Republik Indonesia Tahun 1945

Undang-undang Nomor 1 Tahun 1946 tentang Peraturan Hukum Pidana (KUHP).

Undang-undang Nomor 8 Tahun 1981 tentang Hukum Acara Pidana (KUHAP).

Undang-undang Nomor 9 Tahun 1998 tentang Kemerdekaan Menyampaikan Pendapat di Muka Umum.

Undang-undang Nomor 2 Tahun 2002 tentang Kepolisian Negara Republik Indonesia.

Peraturan Pemerintah Nomor 58 Tahun 2010 tentang Perubahan Atas Peraturan Pemerintah Nomor 27 Tahun 1983 tentang Pelaksanaan Kitab Undangundang Hukum Acara Pidana.

Peraturan Kepala Kepolisian Republik Indonesia Nomor 7 Tahun 2012 tentang Tata Cara Penyelenggaraan Pelayanan, Pengamanan dan Penanganan Perkara Penyampaian Pendapat di Muka Umum.
Peraturan Kepala Badan Pemelihara Keamanan Kepolisian Republik Indonesia Nomor 1 Tahun 2012 tentang Peleton Pengurai Massa.

Peraturan Kepala Kepolisian Republik Indonesia Nomor 23 Tahun 2010 Tentang Susunan Organisasi dan Tata Kerja Pada Tingkat Kepolisian Resor dan Kepolisian Sektor

Prosdur Tetap Kepolisian Republik Indonesia Nomor 1 Tahun 2010 tentang Penanggulangan Anarki.

Peraturan Kepala Kepolisian Republik Indonesia Nomor 16 Tahun 2006 tentang Pedoman Pengendalian Massa.

Himpunan Bujuklak, Bujuklak dan Bujukmin Proses Penyidikan Tindak Pidana, Jakarta, Kepolisian Negara Republik Indonesia Markas Besar, 2000. 